\title{
The Influence of Albumin/glutaraldehyde Sealant in Early Results After Acute Type A Aortic Dissection
}

\author{
HOREA FEIER ${ }^{1,2 *}$, PETRE DEUTSCH ${ }^{1,2}$, MARIAN GASPAR ${ }^{1,2}$, SORIN URSONIU 2 \\ IInstitute for Cardiovascular Diseases, Department of Cardiovascular Surgery, 13A Gh. Adam Str., 300310, Timisoara, Romania \\ 2University of Medicine and Pharmacy Timisoara, 2 Eftimie Murgu Sq.,300041, Timisoara, Romania

\begin{abstract}
Mortality after acute type $A$ aortic dissection ( $A A A D)$ is some of the highest in cardiac surgery. The dissected tissues are fragile and provide a thin layer for performing the aortic anastomoses. We study the influence of a mixture of bovine serum albumin $(45 \%, w / v)$ and glutaraldehyde $(10 \%, w / v)$ in a 4:1 ratio on bleeding and early results ( $<30$ days) after $A A A D$ repair.
\end{abstract}

Keywords: aorta; dissection; glutardehyde; bovine serum albumin; Bioglue

Surgical repair of an acute type A aortic dissection (AAAD) remains an extremely challenging procedure. Early mortality is the highest of any cardiac surgical procedure, with the exception of post-infarction ventricular septal rupture [1]. The dissected aortic layers provide a less than ideal material for performing the proximal and distal anastomoses. Early mortality can result from multiple systems and organ failure, metabolic acidosis, aortic rupture or bleeding [2-4].

Variables that affect mortality in AAAD have been extensively studied. Serum creatinine on arrival, preoperative shock, presence of tamponade, cross clamp time, bypass time, malperfusion and postoperative complications have all been implicated in early and late survival [5-7].

Usage of surgical sealant in this setting has been proposed as early as 1977 [8]. The material consisted of gelatin, resorcinol and formaldehyde $(18 \% \mathrm{w} / \mathrm{v})$, which cross-linked to form a stable compound (GRF glue). Concerns over the toxicity of formaldehyde prevented the product from obtaing the FDA approval in the US, however it was widely used in Europe. A novel compound was introduced in 2000, that consisted of a different chemical formula and gained FDA and CE approval. We evaluated the use of this sealant on early results ( $<30$ days) in the setting of AAAD.

\section{Experimental part}

We retrospectively analyzed all admissions for AAAD in our institution between J anuary 2002 and December 2017. AAAD was defined as an aortic dissection diagnosed less than 14 days after the onset of symptoms. During this period, 163 patients were admitted with the above diagnosis. Five patients were deemed too sick to be operated upon and were treated conservatively. We performed 158 consecutive surgeries for repair of AAAD. Three patients had incomplete preoperative data while two were lost to follow-up. Our final sample included 153 patients.

Patients were diagnosed on the basis of a contrastenhanced chest CT scan and/or transthoracic ultrasonography. Most patients were operated in emergency in the $24 \mathrm{~h}$ that followed admission $(n=137$, $89.13 \%)$.

\section{Surgical sealant}

We used no surgical sealant prior to 2013. Sample A in our study was composed by patients who did not receive any sealant, prior or after that date. Sample B were those in which we used Bioglue, produced by Cryolife, Kennesaw, USA, and those patients were included in sample $B$. This compound consists of purified bovine serum album in $(45 \%$, $\mathrm{w} / \mathrm{v})$ and glutaraldehyde ( $10 \%, \mathrm{w} / \mathrm{v})$. The two components are dispensed from a double-barrel syringe, mix within the delivery tip in a 4:1 ratio in a delivery system and applied to sites of interest. The principle is similar to that of the original GRF glue: glutaraldehyde crosslinks covalently to the amino fragments of lysine aminoacid found in albumin and at the repair site, producing a strong and durable seal, that is independent from the coagulation cascade of the patient (fig. 1). Glutaraldehyde also links to lysine residues found in other proteins in tissues, which accounts for its very good tissue adhesion properties. When applying this sealant it is imperative that all blood be drained from the site, as the glutaraldehyde component will cross-link to it, too, thus reducing its effectiveness. Bioglue had gained FDA approval in 2001.

\section{Surgical technique}

Stable patients were peripherally cannulated prior to sternotomy using the axillary or femoral arteries. In

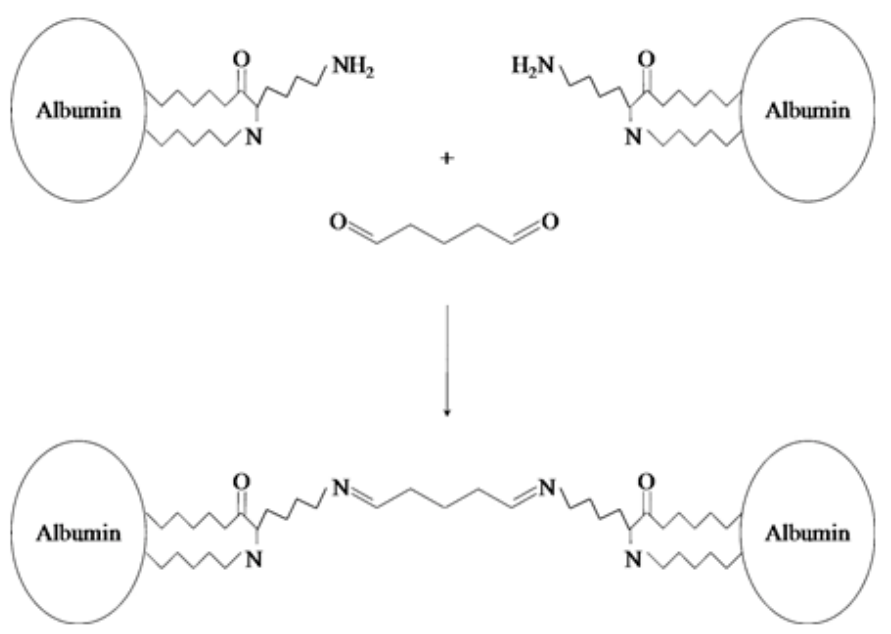

Fig. 1. Mechanism of action of Bioglue sealant: linking of aminolysine residues in albumin by glutaraldehyde, to form a stable polymer (reproduced with permission from [9]). 
unstable patients we performed sternotomy and a limited pericardotomy in order to relieve cardiac tamponade, and cannulated afterwards. Venous inflow was obtained via the right atrium in all patients. The left side of the heart was vented using the right superior pulmonary vein. The patient was cooled to a core temperature of 25 degreec Celsius. The aorta was crossclamped just before reaching this temperature, transected and a dose of cardioplegia was delivered via the coronary ostia. The ascending aorta was inspected for the entry-site of the dissection. The distal anastomosis was performed using either a closed (44.4\%) (or open distal (55.5\%) technique, according to surgeon preference. When performing an open distal anastomosis, cerebral protection was achieved using antegrade cerebral perfusion at a rate of $10 \mathrm{~mL} / \mathrm{kgc} / \mathrm{min}$. Surgical sealant was applied between the layers of the dissected aortic arch after 2013 and those layers were fixed for 3-4 min using Borst clamps. After completing the distal anastomosis systemic perfusion was resumed and the patient was rewarmed in an antegrade fashion using either the previously cannulated axillary artery or a side-branch in the aortic prosthesis. The proximal anastomosis was performed next. The root and aortic valve were assessed. Reasons for performing complete root resection were extensive dissection involving more than the non-coronary sinus, a dilated aortic root $(>5 \mathrm{~cm})$ or an abnormal aortic valve. In such cases it was replaced using a conduit graft, root reimplantation or remodeling techniques. The aortic root was treated conservatively, in most cases, by reapparoximating the dissecting layers with surgical glue (Bioglue, Kennesaw, USA) for 3-4 min using Borst clamps and reinforcing them with generous outer Teflon felts.

\section{Statistical analysis}

Continuous variables were expressed as mean \pm SD. Categorical variables were presented as percentages. Student's t-test with or without Satterwaithe's correction was used on normally distributed continuous variables. Mann-Whitney's ranksum test was used for the other continuous variables. For categorical variables we employed Fisher's exact test. Univariate analyses were performed in order to determine the variables associated with early mortality ( $<30$ days). Variables that achieved a $p$ value $<0.2$ in the univariate analysis were introduced in a logistic regression model with early death as the dependent variable. Postoperative complications were compared on these groups: bioglue/no-bioglue. In all cases, a $p$ value $<0.05$ was deemed as statistically significant.

\section{Results and discussions}

There were 106 males (69.28\%) and 47 females $(30.72 \%)$, aged $55.89 \pm 12.8$ years (range $14-82$ years). Risk factors included hypertension ( $82.89 \%)$, diabetes (7.84\%), bicuspid aortic valve (9.80\%) and obesity (29.41\%). Eight cases $(5.23 \%$ ) occurred after previous cardiac surgical procedures: seven aortic valve replacements and one triple coronary artery bypass. One patient, aged 14, had untreated aortic coarctation, while five (3.27\%) had Marfan syndrome.

More than a third of the patients (35.95\%) had a pericardic effusion $>=10 \mathrm{~mm}$ on preoperative transthoracic ultrasonography. Severe aortic incompetence was found in $35.29 \%$ of patients. The size of the ascending aorta was $5.29 \pm 1.18 \mathrm{~cm}$. Mean ejection fraction was $53.42 \pm 6.5 \%$.

\section{Early results}

There were $32.03 \%$ early deaths in our cohort. Univariate analysis found prebypass $\mathrm{pH}(\mathrm{p}<0.01)$, prebypass base deficit $(p<0.01)$, cardiogenic shock $(p<0.01)$, Penn nonAa $(p<0.001)$, serum creatinine $(p<0.01)$, a pericardial effusion $>10 \mathrm{~mm}(p<0.01)$, ejection fraction $(p=0.03)$ and entry site outside the ascending aorta $(p=0.04)$ as significantly linked to early death (table 1). Logistic regression performed with early death as the dependent variable, found entry site outside the ascending aorta $(\mathrm{OR}=2.86,95 \% \mathrm{Cl}=1.10-7.48, \mathrm{p}=0.03)$, cardiogenic shock on arrival $(\mathrm{OR}=3.35,95 \% \mathrm{Cl}=1.13-9.89, \mathrm{p}=0.02)$,

\begin{tabular}{|c|c|c|c|}
\hline Variable & Survivors (\%) & Deceased $(\%)$ & $\mathrm{p}$ \\
\hline Age (y) & $54.87 \pm 11.96$ & $58.04 \pm 14.33$ & 0.15 \\
\hline Male sex & 72.12 & 63.27 & $0.34^{--}$ \\
\hline \multicolumn{4}{|l|}{ Risk factors } \\
\hline Arterial hypertension & 79.61 & $89.80^{-}$ & $0.16^{-}$ \\
\hline Diabetes & 5.77 & 12.24 & 0.2 \\
\hline Body mass index & $28 \pm 4.92$ & $29.92 \pm 7$ & 0.21 \\
\hline Marfan Syndrome & 3.85 & 2.04 & 1.00 \\
\hline Bicuspid aortic valve & 10.58 & 8.15 & 0.77 \\
\hline Redo procedure & $6.73^{-}$ & $2.04^{-}$ & 0.43 \\
\hline \multicolumn{4}{|l|}{ Presentation } \\
\hline Penn non $\mathrm{Aa}$ & $26.92^{-}$ & 59.18 & $<0.001$ \\
\hline Pericardial fluid $>10 \mathrm{~mm}$ & $27.88^{-}$ & 53.06 & $<0.01$ \\
\hline Cardiogenic shock & 37.93 & 62.07 & $<0.001$ \\
\hline Malperfusion & 56.25 & 43.75 & $0.13^{--}$ \\
\hline Severe aortic insufficiency & 37.50 & 30.61 & 0.47 \\
\hline Aorta size $(\mathrm{mm})$ & $5.36 \pm 1.24$ & $5.15 \pm 1.04$ & $0.29^{\circ}$ \\
\hline Ejection fraction & $54.02 \pm 6.41^{-}$ & $51.63 \pm 6.24^{-}$ & 0.03 \\
\hline Entry site outside the ascending aorta & $14.42 \%$ & $28.57 \%$ & $0.04^{-}$ \\
\hline \multicolumn{4}{|l|}{ Lab values } \\
\hline Creatinine (mg/dl) & $1.32 \pm 0.85$ & $1.7 \pm 0.82$ & 0.01 \\
\hline ALAT & $89.38 \pm 200$ & $205.73 \pm 450.23$ & 0.13 \\
\hline ASAT & $113.16 \pm 276.54$ & $216.59 \pm 472.16$ & 0.23 \\
\hline \multicolumn{4}{|l|}{ Acid base status } \\
\hline Prebypass base deficit & $3.63 \pm 4.60$ & $7.04 \pm 6.70^{\circ}$ & $<0.001$ \\
\hline Prebypass $\mathrm{pH}$ & $7.34 \pm 0.08$ & $7.26 \pm 0.13$ & $<0.001$ \\
\hline
\end{tabular}

Table 1

UNIVARIATE PREOPERATIVE RISK ASSESSMENT 


\begin{tabular}{|c|c|c|c|c|}
\hline Variable & Odd Ratio & $\mathrm{p}$ & \multicolumn{2}{|c|}{$95 \% \mathrm{CI}$} \\
\hline Creatinine & 1.20 & 0.29 & 0.81 & 1.97 \\
\hline Hypertension & 1.39 & $0.60^{\circ}$ & 0.40 & 4.79 \\
\hline Age & $1.01^{-}$ & 0.55 & 0.97 & 1.04 \\
\hline Ejection fraction & 0.96 & 0.32 & $0.90^{\circ}$ & 1.03 \\
\hline Cardiogenic shock & 3.35 & 0.02 & 1.13 & 9.89 \\
\hline Entry site & 2.86 & 0.03 & $1.10^{-}$ & 7.48 \\
\hline Pericardial effusion $>10 \mathrm{~mm}$ & 0.95 & 0.92 & 0.35 & 2.57 \\
\hline Prebypass base deficit & 0.97 & 0.69 & 0.86 & 1.09 \\
\hline Prebypass $\mathrm{pHx} 100$ & 0.93 & 0.02 & 0.88 & 0.99 \\
\hline Malperfusion & 1.96 & 0.17 & 0.74 & 5.20 \\
\hline
\end{tabular}

Table 2

MULTIVARIATE RISK ANALYSIS FOR EARLY DEATH prebypass $p \mathrm{H}(\mathrm{OR}=0.93,95 \% \mathrm{Cl}=0.88-0.99, \mathrm{p}=0.02)$ as independent predictors of early death (table 2).

\section{Intraoperative use of bioglue}

There were differences in intraoperative variables between these two groups (bioglue use, yes/no): crossclamp time was shorter $(108.04 \pm 36.85$ vs. $129.45 \pm 53.71 \mathrm{~min}, p<0.01$ ), circulatory arrest time $(30.67 \pm 15.40$ vs. $38.89 \pm 19.56, p=0.02)$ and a strong tendency for shorter bypass times (190.74 \pm 67.95 vs. $217.52 \pm 98.41, p=0.06$ ) in patients with Bioglue use. These differences can be explained mostly by the experience of the surgeons and the quality and speed of the surgical repair, rather than Bioglue use: patients prior to 2013 had longer crossclamp times ( $129.60 \pm 56.38$ vs. $110.96 \pm 36.61$ min, $p<0.01)$, longer cardiac arrest times $(39.2 \pm 21.3$ vs. $31.72 \pm 14.52, p=0.05$ ), but bypass times were the same $(216.05 \pm 100.82$ vs. $196.02 \pm 70.92, p=0.15)$. It seems that Bioglue use mainly influences bypass times: the better haemostasis achieved by using it can avoid surgical repair of the bleeding sites performed on pump, and thus shorten bypass times.

\section{Bioglue use and postoperative evolution}

Bleeding was reduced in patients with Bioglue: $1150 \pm 1198 \mathrm{ml}$ vs. $1905 \pm 2144(p=0.01)$. They received fewer units of blood cells $(2.32 \pm 2.03$ vs. $4.85 \pm 4.35$, $p<0.01$ ), however the rate of reexploration for bleeding or cardiac tamponade was not significantly lower: $23.33 \pm 33.77, p=0.19$ (fig. 2). These two groups exhibited similar postoperative complications, with the exception of cerebrovascular accident $(6.67 \%$ vs. $20.78 \%, p=0.02)$.

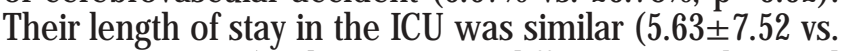
$5.93 \pm 6.94, p=0.8)$. There was no difference in observed rates of early mortality with Bioglue use: there were $29 \%$

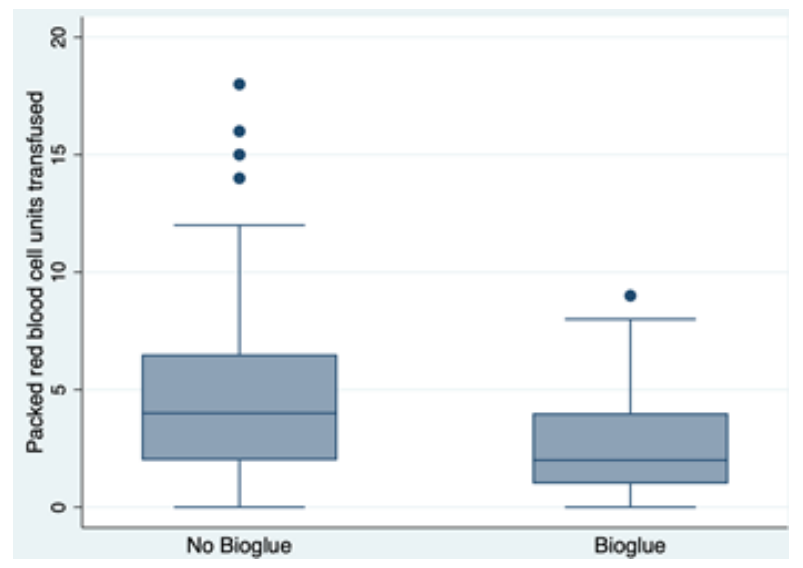

Fig. 2. Boxplot of transfusion requirements in the two groups deaths in patients who received no surgial sealant vs. $20 \%$ rate of death in those who did $(p=0.491)$.

The treatment of AAAD is fraught with high mortality (20-40\% [1-3]) due to the complex nature of the disease that can affect multiple organs and systems in a short time frame. The frailty of aortic tissues means that bleeding from the anastomotic sites remains a major problem in this type of surgery. The first surgical sealant used human fibrinogen, calcium and human thrombin and was proposed in cardiovascular surgery by Spangler in 1974, however, concerns about the potential transmission of viral particles by the use of human donor plasma prevented its FDA clearance. The compound was nevertheless used widely in Europe under the name Tissucol (Tissucol, ImmunoAG, Vienna, Austria). Laurian reported the use of a mixture of gelatin-resorcinol and formaldehyde as an alternative to fibrine sealants in vascular and cardiovascular surgery in 1977 [8]. It had an exceptionally high efficiency in sealing the dissected aortic layers and anastomotic sites [10]. It worked through crosslinking the amino- fragments of gelatin and resorcin by formaldehyde, yielding a threedimensional stable polymer that had a high bonding power to tissue proteins (much bigger than fibrine-based sealants). The main problem with GRF (also called French glue), was the potential toxicity of formaldehyde to surrounding tissues, which prevented it from getting the FDA approval. Bioglue works in a similar fashion, but it uses glutaraldehyde $10 \%(\mathrm{w} / \mathrm{v})$ as a polymerizing agent [11]. It is delivered via a double-barreled syringe, which contains the two components. Its polymerization at the site of application occurs within 2-3 min. The exposure of bovine serum albumin, extracellular matrix and cell surfaces to glutaraldehyde causes their lysine molecules to bind to each other forming a stable bond. Furthermore, modern vascular prostheses used in AAAD surgery for replacement of the diseased segment are all coated with albumin for haemostasis- this enables Bioglue to also bind to their surface.

Bioglue use has been associated with inflammation and tissue necrosis that can lead to false aneurysm formation $[12,13]$ just as GRF has, but its rate seems to be, nevertheless, inferior to formaldehyde-based sealants [14]. Other reports acknowledged its hemostatic properties, however they also noted impaired grow th and anastomotic stricture formation in pediatric patients [15].

Our sample consisted of almost all patients admitted in our institution with AAAD over a 15-year period. Only five cases were deemed too sick to be treated surgically and this attitude may have contributed to our mortality (32.03\%), which is higher than reported in the IRAD database [2]. Bioglue significantly reduced bleeding and transfusion rates, how ever it did not influence complications and early mortality rates and this finding is consistent with other reports [16]. 


\section{Limitations}

Our study was retrospective and as such has all the limitations of this type of research. A prospective one would better define which factors, measured at the time of admission, are modifiable and to what extent.

\section{Conclusions}

Bioglue use was associated with lower bleeding and transfusion rates, however it did not influence complications and early mortality rates in our sample. Other preoperative and procedure-related variables, such as cardiogenic shock on presentation, preoperative metabolic acidosis and entry site of the dissection seem to play a more prominent role in influencing results.

\section{References}

1.TRIMARCHI S, NIENABER CA, RAMPOLDI V, MYRMEL T, SUZUKI T, MEHTA RH, BOSSONE E, COOPER JV, SMITH DE, MENICANTI L, FRIGIOLA A, OH JK, DEEB MG, ISSELBACHER EM, EAGLE KA, Contemporary results of surgery in acute type $A$ aortic dissection: The International Registry of Acute Aortic Dissection experience, J Thorac Cardiovasc Surg, 129, 2005, p. 112 doi:10.1016/j.jtcvs.2004.09.005 2.PAPE LA, AWAIS M, WOZNICKI EM, SUZUKI T, TRIMARCHI S, EVANGELISTA A, MYRMEL T, LARSEN M, HARRIS KM, GREASON K, DI EUSANIO M, BOSSONE E, MONTGOMERY DG, EAGLE KA, NIENABER CA, ISSELBACHER EM, O'GARA P, Presentation, Diagnosis, and Outcomes of Acute Aortic Dissection: 17-Year Trends From the International Registry of Acute Aortic Dissection, J Am Coll Cardiol, 66, 2015, p. 350. doi:10.1016/j.jacc.2015.05.029

3.CONZELMANN LO, WEIGANG E, MEHLHORN U, ABUGAMEH A, HOFFMANN I, BLETTNER M, ETZ CD, CZERNY M, VAHL CF, Mortality in patients with acute aortic dissection type $A$ : analysis of pre- and intraoperative risk factors from the German Registry for Acute Aortic Dissection Type A (GERAADA), EurJ Cardiothorac Surg, 49, 2016, e44. doi:10.1093/ejcts/ezv356

4.FEIER H, COZMA D, SINTEAN M, DEUTSCH P, URSONIU S, GASPAR M, MORNOS C, How Much Malperfusion Is Too Much in Acute Type A Aortic Dissections?, J Clin Med, 8, 2019, p. 304. doi:10.3390/jcm8030304 5.TSAI TT, EVANGELISTA A, NIENABER CA, TRIMARCHI S, SECHTEM U, FATTORI R, MYRMEL T, PAPE L, COOPER JV, SMITH DE, FANG J, ISSELBACHER E, EAGLE KA, Long-term survival in patients presenting with type $A$ acute aortic dissection: insights from the International Registry of Acute Aortic Dissection (IRAD), Circulation, 114, 2006, p. I350 doi:10.1161/CIRCULATIONAHA.105.000497
6.RAMPOLDI V, TRIMARCHI S, EAGLE KA, NIENABER CA, OH JK, BOSSONE E, MYRMEL T, SANGIORGI GM, DE VINCENTIIS C, COOPER JV, FANG J, SMITH D, TSAI T, RAGHUPATHY A, FATTORI R, SECHTEM U, DEEB MG, SUNDT TM, ISSELBACHER EM, Simple risk models to predict surgical mortality in acute type $A$ aortic dissection: the International Registry of Acute Aortic Dissection score, Ann Thorac Surg, 83, 2007, p. 55 doi:10.1016/j.athoracsur.2006.08.007

7.ZHANG J , JIANG Y, GAO C, FENG J, WANG A, Risk factors for hospital death in patients with acute aortic dissection, Heart Lung Circ, 24, 2015, p. 348 doi:10.1016/j.hlc.2014.10.009

8.LAURIAN C, GIGOU F, GUILMET D. [Gelatin resorcin formaldehyde glue in vascular surgery (authors transl)], Nouv Presse Med, 6, 1977, p. 3221

9.BHATIA SK. Biomaterials for clinical applications. 2010.

10.GUILMET D, BACHET J, GOUDOT B, LAURIAN C, GIGOU F, BICAL $O$, BARBAGELATTA M, Use of biological glue in acute aortic dissection. Preliminary clinical results with a new surgical technique, J Thorac Cardiovasc Surg, 77, 1979, p. 516

11.FDA DS, 2001. FDA approval BioGlue Surgical Adhesive: P010003. 12.LUK A, DAVID TE, BUTANY J. Complications of Bioglue postsurgery for aortic dissections and aortic valve replacement, J Clin Pathol, 65, 2012, p. 1008 doi:10.1136/jclinpath-2012-200809

13.MA WG, ZIGANSHIN BA, GUO CF, ZAFAR MA, SIELLER RS, TRANQUILI M, ELEFTERIADES JA, Does BioGlue contribute to anastomotic pseudoaneurysm after thoracic aortic surgery?, J OURNAL OF THORACIC DISEASE, 9, 2017, p. 2491 doi:10.21037/jtd.2017.06.120 14.KIRSCH M, GINAT M, LECERF L, HOUEL R, LOISANCE D, Aortic wall alterations after use of gelatin-resorcinol-formalin glue, Ann Thorac Surg, 73, 2002, p. 642 doi:10.1016/S0003-4975(01)03008-9

15.LEMAIRE SA, SCHMITTLING ZC, COSELLI I S, UNDAR A, DEADY BA, CLUBB FJ, FRASER CD, Bioglue surgical adhesive impairs aortic growth and causes anastomotic strictures, Ann Thorac Surg, 73, 2002, p. 1500 doi:10.1016/S0003-4975(02)03512-9

16. HEWITT CW, MARRA SW, KANN BR, TRAN HS, PUC MM, CHRZANOWSKI FA, TRAN JL, LENZ SD, CILLEY JH, SIMONETTI VA, DELROSSI AJ, BioGlue surgical adhesive for thoracic aortic repair during coagulopathy: efficacy and histopathology, Ann Thorac Surg, 71, 2001, p. 1609 doi:10.1016/S0003-4975(01)02424-9

$\overline{\text { Manuscript received: } 12.12 .2018}$ 